\title{
LI. On supersaturation of salt-solutions
}

\author{
W.W.J. Nicol M.A. D.Sc.
}

To cite this article: W.W.J. Nicol M.A. D.Sc. (1885) LI. On supersaturation of salt-solutions , Philosophical Magazine Series 5, 19:121, 453-461, DOI: 10.1080/14786448508627701

To link to this article: http://dx.doi.org/10.1080/14786448508627701

曲 Published online: 29 Apr 2009.

Submit your article to this journal

Џ Article views: 2

Q View related articles $₫$ 
I am sorry to say that I did not see this clearly at first, nor do $I$ see it now as clearly as I should like, and I have accordingly wasted three days in an attempt to take account of conduction of heat, or at least of a certain minimum amount of it, as if it were an essential part of the process; the raising of heat-potential by the current in certain cases being only accountable, as it seemed to me, by reason of a definite and calculable amount of degradation by conduction; after the manner of a water-ram.

Liverpool, 8th May, 1885.

LI. On Supersaturation of Salt-Solutions. By W. W. J. Nicol, M.A., D.Sc., Lecturer on Chemistry, Mason College, Birmingham*.

"Le sulfate de soude dissous dans l'eau à des températures quelconques est anhydre. Il n'y a de solution sursaturée." $†$

REFORE I proceed to give an account of my experiments $\mathrm{B}$ on this subject and the conclusions based on them, it is necessary to point out that there are two distinct kinds of supersaturation.

Supersaturation, in general, may be defined as-

The existence in solution of a larger quantity of salt than the water is normally capable of holding in solution at the temperature of experiment.

Or as clearly expressed by Mulder $\ddagger$ -

"Oververzadiging is: meer in oplossing hebben bij cene zekere temperatuur dan bij die temperatuur in oplossing kan overgaan, wanneer men begint met het vaste zout en dat behandelt met water bij die temperatuur. . . Oververzadiging is dus: behoud van een toestand, aan het zout gegeven door eene hoogere temperatuur."

"Supersaturation is the holding in solution at a given temperature more salt than can be dissolved at that temperature, starting with the solid salt and treating it with water at that temperature. It is thus the possession of a condition which is conferred on a salt by a higher temperature."

Supersaturation as thus defined is common to all salts without exception. But it will be seen on reflection that, as I have said, there are two kinds :-

1st. That occurring in presence of undissolved salt.

* Communicated by the Author, having been read before the Royal Society of Edinburgh, April 1885.

+ Loewel, Ann. d. Chim. et Phys. [3] xlix. p. 51.

+ Bijdragen tot de Gieschiedents van het scheikundig gebonden IVater (Potterdam, 1864). 
2nd. That which manifests itself only in the absence of undissolved salt.

Of the above, the former occurs with all salts, hydrated or anhydrous in the solid form. Its existence is dependent solely on the fact that a finite time is necessary to permit of the establishment of equilibrium or saturation in a solution. When a hot saturated solution is cooled to the temperature. of the air, the first portions of the excess of salt crystallize out at once, but more slowly as the excess becomes less and less, until when equilibrium is nearly perfect separation of solid salt is extremely slow. This has been commented on by Kremers under the name of "Inertia,"* and is a fertile source of error in determinations of solubility. I have myself detected traces of this form of supersaturation even in the case of solutions which have been prepared at a high temperature and, after cooling, agitated for twenty-four hours with the solid salt; the percentage dissolved was frequently slightly greater than in the case of solutions prepared from solid salt and water without previous heating $\dagger$.

This is, I hope to show, true supersaturation; it is never well marked, and is not permanent, the excess of salt thus remaining in solution being exceedingly small, and becoming less and less with time.

The phenomenon usually termed supersaturation is the second of the two kinds I have distinguished, and is quite distinct from the former. It occurs only with hydrated salts, and is well marked and permanent. The amount of salt thus retained may be very large, and crystallization may, under certain conditions, be delayed indefinitely. It is manifested whenever a strong warm solution of a hydrated salt is allowed to cool out of contact with the air or in contact with air which has been heated or filtered through cotton-wool. In nearly all cases such solutions remain permanently liquid, depositing crystals on strong cooling, which dissolve again on the application of a gentle heat, such as that of the hand. No crystallization is caused by shaking or by the passage of electricity; but crystallization takes place at once on the addition of a crystal of the hydrated salt.

It is with such cases of supersaturation that this paper has to deal, and I hope to be able to show that, though a solution may deposit salt under the above conditions, yet it is not really supersaturated. I have confined myself strictly to the state of the solutions, and have no remarks to offer on the causes which bring about erystallization.

\footnotetext{
* Pogg. Ann. lxxxv. p. 41.

$\dagger$ Phil. Mag. June (Suppl.) 1884.
} 
The question I have set myself is: What is a (so-called) supersaturated solution? And the answer I have obtained is a very simple, though at first sight strange one. It is a nonsaturated or just-saturated solution of the anhydrous salt.

It is nearly three years since I made my first experiments on this subject, by determining the density of supersaturated solntions of sulphate and thiosulphate of sodium before and after crystallization; but at that time the results obtained had no meaning to me, and it is only recently that $I$ have been able to interpret them. The modus operandi was as follows:A quantity of salt was placed in a weighed specific-gravity bottle, which was again weighed. A quantity of water was added, and the whole reweighed; then some paraffin-oil of known density was added, and the bottle was placed in hot water till complete solution was effected. After cooling, the bottle was filled up with paraffin, the stopper inserted, and then placed in a constant-temperaturo bath for some time, and finally dried and weighed. When the stopper was removed, a minute crystal of the salt under examination, when dropped through the paraffin into the solution, produced instant crysstallization. After three or four hours in the constant-temperature bath crystallization was assumed to be complete, and, after refilling with paraffin, the bottle was again weighed. From the data thus obtained it was easy to caleulate the

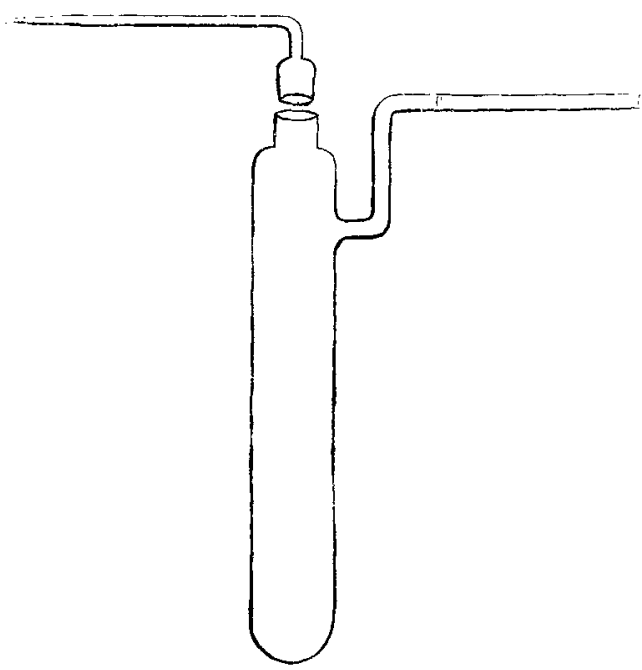

density of the solution, and also that of the mixture of salt and saturated solution resulting from the crystallization. It 
was found that separation of $\mathrm{Na}_{2} \mathrm{SO}_{4} 10 \mathrm{aq}$. was attended by expansion, $\mathrm{Na}_{2} \mathrm{~S}_{2} \mathrm{O}_{3} 5$ aq. by contraction; and it was this contradictory behaviour of the two salts that caused me to abandon the experiments for the time.

In more recent experiments I employed the apparatus in the figure, which is in many respects more accurate and more easily worked with than a bottle; at the same time I saw the futility of determining the density after crystallization: the whole secret was to be found in the solution before solidification. Expansion or contraction was a mere accident peculiar to the salt employed.

Table I. contains the results of all my experiments calculated for anhydrous salt-molecules per hundred water-molecules with the corresponding apparent molecular volumes $\left(\frac{r}{n}\right)$ of each salt-molecule.

TABLE I.

\begin{tabular}{|c|c|c|c|c|}
\hline \multicolumn{5}{|c|}{$n\left(\mathrm{Na}_{2} \mathrm{~S}_{2} \mathrm{O}_{3}\right) 100 \mathrm{H}_{2} \mathrm{O}$} \\
\hline$t^{\circ}$ & $n$ & Density. & Mol, rol. & $\frac{M V-1800 .}{n .}$ \\
\hline $\begin{array}{l}20 \\
" \\
" \\
" \\
" \\
" \\
"\end{array}$ & $\begin{array}{c}7 \cdot 665 * \\
9 \cdot 216 \\
10 \cdot 057 \\
11 \cdot 071 \\
11 \cdot 679 \\
12 \cdot 132 \\
15 \cdot 149 \\
20 \cdot 000+\end{array}$ & $\begin{array}{l}1.38896 \\
1 \cdot 43835 \\
1 \cdot 46231 \\
1 \cdot 49392 \\
1 \cdot 50136 \\
1 \cdot 50383 \\
1 \cdot 39006 \\
1.67335\end{array}$ & $\begin{array}{l}2167 \cdot 84 \\
2263 \cdot 80 \\
2317 \cdot 54 \\
2357 \cdot 70 \\
2428 \cdot 03 \\
2471 \cdot 56 \\
2637 \cdot 37 \\
2964 \cdot 20\end{array}$ & $\begin{array}{l}47 \cdot 99 \\
50 \cdot 33 \\
51 \cdot 46 \\
52 \cdot 01 \\
53 \cdot 77 \\
55 \cdot 35 ? \\
55 \cdot 29 \\
58 \cdot 21\end{array}$ \\
\hline \multicolumn{5}{|c|}{$n\left(\mathrm{Na}_{2} \mathrm{SO}_{4}\right) 100 \mathrm{H}_{2} \mathrm{O}$} \\
\hline $\begin{array}{l}20 \\
", \\
", \\
", \\
",\end{array}$ & $\begin{array}{l}\cdot 5 \\
1 \cdot 0 \\
1 \cdot 847 * \\
3 \cdot 193 \\
4 \cdot 442 \\
4 \cdot 729 \\
6 \cdot 244\end{array}$ & $\begin{array}{l}1 \cdot 03466 \\
1 \cdot 06744 \\
1 \cdot 11733 \\
1 \cdot 19215 \\
1 \cdot 25855 \\
1 \cdot 26698 \\
1 \cdot 34014\end{array}$ & $\begin{array}{l}1808 \cdot 32 \\
1819 \cdot 31 \\
1845 \cdot 77 \\
1890 \cdot 18 \\
1931 \cdot 40 \\
1969 \cdot 35 \\
2004 \cdot 71\end{array}$ & $\begin{array}{l}16 \cdot 64 \\
19 \cdot 31 \\
24 \cdot 71 \\
28 \cdot 25 \\
29 \cdot 58 \\
31 \cdot 87 \\
32 \cdot 79\end{array}$ \\
\hline
\end{tabular}

In the case of sodium thiosulphate, the first solution determined was that saturated for the hydrated salt at $20^{\circ} \mathrm{C}$, and after that solutions of varions strengths up to that consisting of the salt fused in its water of crystallization. With sodium sulphate the solutions ranged in strength from the half-molecule up to one containing more than six molecules of salt per 
hundred water-molecules; this last is the strongest solution that can be conveniently worked with. In the case of both salts the molecular volume constantly increases with the concentration, very rapidly at first, and then more slowly, just as it does in the case of an ordinary solution of an anhydrous salt, such as potassium nitrate. The chief point of importance is the absence of any abrupt break above the ordinary saturation-point; there is no discontinuity, the steady increase is unbroken; there is nothing in the numbers for the molecular volumes to indicate a difference in the constitution of the solution. I ought to add that, owing to the unavoidable loss of water during the heating necessary for the solution of the salt, it is not to be expected that the density determinations should be as accurate as those of ordinary solutions; not much reliance can be placed, I fear, on the fourth figure; not by any means so much as on the fifth figure in other cases: the effect of this is to affect the molecular volume in the first decimal to the extent of \pm 5 .

It would seem, then, that these solutions were simply solutions of the anhydrous salt which are yet unsaturated. I have already expressed my conviction that a salt in solution parts with its water of crystallization *, and attempted to prove it by experiment. If this were correct, and the supersaturated solution such as I conceived it to be, it followed that anhydrous sodium sulphate should dissolve in a so-called supersaturated solution; in other words, a solution saturated by contact with crystals of a hydrated salt should be able to dissolve that salt when dehydrated.

To test this a wide-mouthed bottle was nearly filled with crystals of $\mathrm{Na}_{2} \mathrm{~S}_{2} \mathrm{O}_{3} 5$ aq., and placed in boiling water. The quantity of salt was nearly 60 grammes; a small, thin glass bulb containing less than a gramme of the dehydrated salt, and sealed, was also placed in the bottle. When the thiosulphate was completely fused, the stopper was put in, and, after cooling slightly, the bottle was placed in water at about $15^{\circ} \mathrm{C}$. Thiosulphate of sodium fuses at $48^{\circ}$ to $50^{\circ} \mathrm{C}$, yet the solution thus obtained was perfectly stable ; no crystallization was caused by gentle shaking. By a smart blow of the bottle on the knee the small bulb was broken, and the dehydrated salt brought in contact with the solution; no crystallization took place; on the contrary, solution was complete in a few seconds. The experiment was repeated with from 4 to $4 \cdot 5$ grms. of $\mathrm{Na}_{2} \mathrm{~S}_{2} \mathrm{O}_{3}$ to 40 grms. of $\mathrm{Na}_{2} \mathrm{~S}_{2} \mathrm{O}_{3} 5$ aq. In this case solution was not complete at the ordinary temperature, but was readily effected by heat. When the solu-

* Phil. Mag. Sept. 1884, p. 181. 
tion thus obtained was cooled, crystals slowly separated out at the air temperature. Some crystals thus obtained were drained as completely as possible from the oily mother-liquor, and then removed and pressed between filter-paper ; in spite of the draining they were found to be imbedded in a mass of the solidified hydrated salt. On heating, the original crystals did not change form, and remained nearly transparent. The total loss of water on the mixture was 17 per cent., corresponding to $\mathrm{Na}_{2} \mathrm{~S}_{2} \mathrm{O}_{3} 2$ aq. The crystals cannot therefore contain more than one molecule of water ; and in view of their transparency and not changing in form on heating, it appears probable that they were anhydrous. The crystalline form was an obtuse rhombohedron. I have not been able to find any account of a salt containing less than five molecules of water.

A solution of sodium sulphate, which was distinctly supersaturated at $20^{\circ} \mathrm{C}$., readily dissolved a considerable quantity of the anhydrous salt when introduced as above, even at $15^{\circ} \mathrm{C}$. Another solution deposited anhydrous salt at $30^{\circ} \mathrm{C}$, which redissolved on cooling to $20^{\circ} \mathrm{C}$.; while $\mathrm{Na}_{2} \mathrm{SO}_{4} 7 \mathrm{aq}$. crystallized out on cooling a few degrees. These crystals, however, quickly dissolved when the bottle was warmed in the hand. The most remarkable feature of these experiments was that in no instance was any caking of the anhydrous salt observed, as would have been the case had it combined with the water to form a hydrate before dissolving; it is, of course, evident that no trace of the normal hydrate was in any case produced, for this would have determined the crystallization of the supersaturated solution.

The only experiments in any way resembling those above described that $I$ have been able to find an account of, are those of Coppet and Thompson.

Coppet* describes the manufacture of supersaturated solutions of sodium sulphate and other salts by the addition of anhydrous or partially dehydrated salt to water. He found that, in order to succeed, it was necessary to exclude unfiltered air and to add the salt in exceedingly small quantities at a time. With sodium sulphate he found that he conld thus obtain a solution containing nearly five times as much anhydrous salt as is contained in a solution prepared from the decahydrated salt at the same temperature. In this case the addition of the anhydrous salt must have been so slow, that when the ordinary saturated solution was produced no decahydrated salt remained undissolved; or it is quite possible that no decabydrated salt is formed by the addition of anhydrous salt to any but very dilute solutions.

* Comptes Rexdus, 1871, vol. 1xxiii. p. 1324. 
Again, J.S.Thompson*, in experimenting with potash-alum, found that a supersaturated solution, prepared by saturating water at $90^{\circ} \mathrm{C}$. with the ordinary hydrate, deposited no crystals on cooling to the ordinary temperature; but that a solution saturated at $95^{\circ} \mathrm{C}$. deposited small clear crystals. On breaking the flask in ice-cold water and washing the crystals, he found on analysis that they were ordinary alum with 24 molecules of water. This was of course to be expected as the natural result of his mode of experiment, for the anhydrous salt or a lower hydrate would at once take up water to form the normal bydrate; while it is equally evident that the crystals could not have been the normal hydrate, or they would have caused erystallization of the supersaturated solution in which they were formed.

There is therefore, it appears to me, little doubt that the so-called supersaturated solutions furnish a further proof of my contention that a salt exists in solution not as a hydrate definite or indefinite, but in the anhydrous state. This may appear a curious statement, but $I$ fail to see what other explanation can be given of the water of crystallization possessing the same volume as the solvent water, as has been proved by the experiments by Ostwald and myself on the molecular volumes of solutions of nearly two handred salts of various metals. This will not appear so strange when it is remembered that it is already pretty generally admitted that double salts as a rule exist only in the solid state, combination taking place only at the moment of crystallization from solution. I have already (loc. cit.) pointed out the fallacy involved in the argument from the heat of hydration ; and the only difficulty that remains is the colour of certain salts in solutions of various degrees of concentration, or in the solid state. Thus anhydrous copper sulphate or the monohydrated salt is colourless, while the pentahydrate and the solution is blue. Again, cobalt chloride is red when hydrated and solid, blue when dehydrated; on the other hand, a strong solution of this salt is red when cold, blue when hot. This has always been regarded as a conclusive proof of the existence of the hydrated salt in at least dilute and cold solutions. But it is more than probable that the whole secret of the above colour-changes lies in the difference in the aggregations of molecules and not in the amount of hydration of the salt. We do not in the least know what multiple of the usual formula for a molecule forms the individual in the solid state or in solution; and it would be by no means a forced explanation of the above colour-changes to attribute them to the

* Journ. Chem. Soc. 1882, vol. xli. p. 382. 
simplification of these aggregations of molecules. It would be quite possible that the volume-changes attending this disgregation would escape detection by the methods I have employed; but the changes in volume produced by hydration or nonhydration are far too large not to be detected by a comparison of the molecular volumes of the solutions, especially when dealing with salts containing a large number of molecules of water of crystallization. I do not at present wish to lay much stress on this explanation; it is, it seems to me, a point which has by no means received the attention which is its due ; but I am convinced that until this is conclusively settled one way or another, it is premature to bring forward colour-changes as the sole evidence in favour of the hydration of salts in solution-a conclusion directly negatived by the molecular volumes of the very salts on the colours of whose solutions the whole hypothesis is based.

Further, such colour-changes are well known to occur in cases where no dehydration or other decomposition can occur, and where the only explanation is to be found in an alteration of the molecular constitution. Numerous instances are given in a paper by Carnelley on the colour of chemical compounds as a function of their atomic weights * ; but one or two may be given here with advantage. Thus, mercuric oxide and red lead are both red when cold, but darken when heated, ultimately becoming almost black though no decomposition has taken place, as is proved by their regaining their original colour on cooling. Again, the temperature of boiling water is sufficient to turn the scarlet cuprous mercuric iodide black, the scarlet colour returning when the salt is cold. The differences in colour of mercuric sulphide are also due to a difference in molecular constitution. But perhaps the most instructive instance of all is to be found in the effect of heat on the hexhydrated cobalt chloride itself : when the solid crystals are gently warmed they change from red to blue without any loss of water, they do not lose their transparency, and the colour-change is found to have extended to the very centre of the crystal.

The results of my experiments may be summarized as follows :-

(1) The individual in solution is not the same as that in the solid state when hydrated salts are considered.

(2) It is to this that supersaturation is due.

(3) A supersaturated solution is a solution of the anhydrous salt, which may or may not be saturated. So long as no disturbing cause operates to bring about combination of

* Phil. Mlag. 1884, xviii. p. 130. 
the salt and water a supersaturated solution differs in no respect from an ordinary solution.

(4) The state of unstable equilibrium existing in a supersaturated solution is analogous to that existing in water cooled below its freezing-point.

(5) It is probable that full hydration of a dehydrated salt previous to solution occurs only when the salt is dissolved in pure water or in a very dilute solution of itself.

LII. On Binocular Glasses adjustable to Eyes having unequal Focal Lengths. By Colonel MaLcolm, R.E., C.B.*

WHETHER many people are born with their eyes differing in focal length or not I cannot say; it is sufficient that I have arrived at a period of life when glasses are necessary to enable me to read with comfort, and also that I found a very highly treasured pair of binocular glasses, by Voigtländer, become yearly more difficult to use, and at last useless; but I found that I could see with equal distinctness with each eye, using only one eye at a time, on condition of a very slight alteration of focus.

Mr. Browning, optician, in the Strand, having tested my eyes for a pair of pince-nez, told me that, as regards the ordinary reading and writing distances at any rate, my eyes were not a pair, and that after a certain age few people's were who had used their eyes much.

Accepting the fact, I set to work to make my binocular glasses once more useful-in this way.

One tube is left untouched; the eyepiece of the other is so arranged that it can be moved through a small range in and out, with reference to the eyepiece of the untouched tube, by turning round a milled ring. An index arrangement is provided.

The unaltered tube is used with one eye and brought to the most perfect focus possible in the ordinary way ; then the other tube is used with the other eye, and by means of the adjustment its definition is made as perfect as may be, the ordinary adjustment not being interfered with. The two eyes are then used together; and the process of adjustment had better be gone over again, as certainly the two eyes do help each other.

The final position of the index-mark is noted; and that holds good for all ranges, as far as I have tried.

Having noted this, you may lend your glasses to your friend,

* Communicated by the Physical Society. The glasses were exhibited at the Meeting held on March 28, 1885.

Phil. Mag. S. 5. Vol. 19. No. 121. June 1885. 2 I 